\title{
@ The Role of Hydromorphone and OPRM1 in Postoperative Pain Relief with Hydrocodone
}

Mark V. Boswell, MD, PhD', M. Elaine Stauble, MD², Gary E. Loyd, MD', Loralie Langman, $\mathrm{PhD}, \mathrm{DABCC}{ }^{3}$, Bronwyn Ramey-Hartung, $\mathrm{PhD}^{4}$, Richard N. Baumgartner, $\mathrm{PhD}^{5}$, William W. Tucker, BS ${ }^{6}$, and Saeed A. Jortani, PhD, DABCC ${ }^{1,6}$

From: ${ }^{1}$ Dept. of Anesthesiology and Perioperative Medicine University of Louisville School of Medicine, Louisville, KY; 2Dept. of Obstetrics and Gynecology, University of Louisville School of Medicine, Louisville, KY; 3Dept. of Lab Medicine and Pathology, Mayo Clinic Rochester, MN; 4PGXL Laboratories, Louisville, $\mathrm{KY}$ 5Dept. of Epidemiology and Population Health, University of Louisville, Louisville, $\mathrm{KY} ;{ }^{6}$ Dept. of Pathology and Laboratory Medicine, University of Louisville School of Medicine, Louisville, KY

Address Correspondence: Dr. Saeed A. Jortan 511 South Floyd Street

Louisville, $\mathrm{KY} 40202$

E-mail: sjortani@louisville. edu

Disclaimer: There was no external funding in the preparation of this manuscript.

Conflict of interest: None.

Manuscript received: 01-12-13 Accepted for publication:

02-14-13

Free full manuscript: www.pain physicianjournal.

com
Background: Postoperative pain management remains a challenge for clinicians due to unpredictable patient responses to opioid therapy. Some of this variability may result from single nucleotide polymorphisms (SNPs) of the human opioid mu-1 receptor (OPRM1) that modify receptor binding or signal transduction. The OPRM1 variant with the highest frequency is the A118G SNP. However, previous studies have produced inconsistent results regarding the clinical effects of A118G on opioid response. We hypothesized that measurement of serum opioid concentrations, in addition to determining total opioid consumption, may provide a more precise method of assessing the effects of $\mathrm{A} 118 \mathrm{G}$ on analgesic response. The current study evaluated the relationship of analgesia, side effects, total hydrocodone consumption, quantitative serum hydrocodone and hydromorphone concentrations, and A118G SNP in postoperative patients following Cesarean section.

Methods: 158 women scheduled for Cesarean section were enrolled prospectively in the study. The patients had bupivacaine spinal anesthesia for surgery and received intrathcal morphine with the spinal anesthetic or parenteral morphine for the first 24 hours after surgery. Thereafter, patients received hydrocodone/acetaminophen for postoperative pain control. On postoperative day 3 , venous blood samples were obtained for OPRM1 A118G genotyping and serum opioid concentrations.

Results: $131(82.9 \%)$ of the subjects were homozygous for the 118A allele of OPRM1 (AA) and 27 $(17.1 \%)$ carried the $G$ allele $(A G / G G)$. By regression analysis, pain relief was significantly associated with total hydrocodone dose in the AA group $(P=0.01)$, but not in the AG/GG group $(P=0.554)$. In contrast, there was no association between pain relief and serum hydrocodone concentration in either group. However, pain relief was significantly associated with serum hydromorphone concentration (a metabolite of hydrocodone) in the AA group ( $P=0.004)$, but not in the $\mathrm{AG} / \mathrm{GG}$ group $(P=0.724)$. Conversely, side effects were significantly higher $(P<0.04)$ in the AG/GG group (mean $=6.4$ ) than in the AA group (mean $=4.4)$, regardless of adjustment for BMI, pain level, or total dose of hydrocodone.

Conclusion: This study found a correlation between pain relief and total hydrocodone dose in patients homozygous for the 118A allele (AA) of the OPRM1 gene, but not in patients with the $118 \mathrm{G}$ allele $(A G / G G)$. However, pain relief in 118A patients did not correlate with serum hydrocodone concentrations, but rather with serum hydromorphone levels, the active metabolite of hydrocodone. This suggests that pain relief with hydrocodone may be due primarily to hydromorphone. Although pain relief did not correlate with opioid dose in AG/GG patients, they had a higher incidence of opioid side effects. The correlations identified in this study may reflect the fact that serum opioid concentrations were measured directly, avoiding the inherent imprecision associated with relying solely on total opioid consumption as a determinant of opioid effectiveness. Thus, measurement of serum opioid concentrations is recommended when assessing the role of OPRM1 variants in pain relief. This study supports pharmacogenetic analysis of OPRM1 in conjunction with serum opioid concentrations when evaluating patient responses to opioid therapy.

Key words: Cesarean section, female gender, genetic polymorphisms, hydrocodone, hydromorphone, opioid Mu 1 receptor, opioid concentrations, serum, OPRM1; rs1799971, postoperative pain

Pain Physician 2013; 16:E227-E235 
U npredictable patient responses to standard opioid therapy make postoperative pain management a challenge for clinicians. The large variation in opioid responses between patients suggests a possible genetic factor. Identification of single nucleotide polymorphisms (SNPs) in the human mu-1 opioid receptor (OPRM1) gene provides a possible mechanism for the observed variability. The most common variant of OPRM1, A118G SNP (rs1799971) results from an asparagine to aspartic acid exchange at residue 40 of the receptor protein, due to an adenine to guanine substitution at nucleotide position 118 (www. ncbi.nlm.nih.gov/sites/varvu?gene $=4988 ; \quad$ accessed 2/22/2013).

Patients homozygous for $118 \mathrm{G}(\mathrm{GG})$ have been reported to require higher morphine doses for pain control (1-7). The incidence of side effects with morphine in relation to genotype is variable in those studies, although Sia et al (5) reported more nausea in homozygous 118A (AA) patients. In human volunteers receiving intravenous alfentanil for relief of electrically induced pain, subjects with the $G$ allele required higher plasma alfentanil concentrations to achieve the same analgesia as the AA group (8). In addition, homozygous GG subjects required higher alfentanil concentrations to achieve the same degree of respiratory depression as the AA subjects. However, recent clinical studies that evaluated pain relief on the basis of opioid dosage requirements question the therapeutic predictive value of OPRM1 polymorphisms $(9,10)$.

Uncertainty surrounding the therapeutic relevance of genetic analysis of OPRM1 may partly reflect the design of previous studies where pain scores and side effects were compared with total opioid consumption and not serum opioid concentrations. Determination of serum opioid concentrations would be expected to avoid the inherent inconsistency associated with using total opioid consumption as a measurement of opioid effectiveness, because variations in opioid consumption may also be due to differences in drug metabolism, including genetic variability in CYP enzymes and the presence of metabolic inhibitors. For that reason, the present study was designed to compare analgesic responses and side effect profiles, by OPRM1 genotype, with quantitative serum opioid concentrations, as well as total opioid consumption. Patients in this study received hydrocodone for postoperative pain control following Cesarean section. Because serum opioid levels were measured, this study also examined the potential role that hydromorphone, an opioid metabolite of hy- drocodone (11-13), may play in the analgesic response to hydrocodone. The hypothesis of this study was that OPRM1 A118G alleles would correlate differently with pain relief, side effects, opioid dose, and serum opioid concentrations.

\section{Methods}

\section{Enrollment of Subjects}

Obstetric patients between the ages of 18 and 45 years requiring Cesarean section, either repeat or elective, at University of Louisville Hospital from December 2008 through Feb 2011 were recruited to participate. Approximately $40 \%$ of potentially eligible subjects agreed to participate and data were collected for 177 women. All patients provided written informed consent and the study protocol was reviewed and approved by the University of Louisville Institutional Review Board and the University of Louisville Hospital Review Board. Women with morbid obesity, unable to speak English or Spanish, or a history of drug abuse were excluded. The first 40 patients enrolled in the study received a bupivacaine spinal anesthetic for Cesarean section, with parenteral morphine injections for pain relief for the first 24 hours. Thereafter, patients were allowed hydrocodone/acetaminophen $(5 \mathrm{mg} / 325 \mathrm{mg}$ or $7.5 \mathrm{mg} / 325 \mathrm{mg}$ ) every 4 hours as needed for pain control. The remainder of the patients received intrathecal morphine (Duramorph $\AA$ ) at the time of the bupivacaine spinal anesthetic, and then hydrocodone/acetaminophen as necessary starting 24 hours after surgery. Patients were allowed ibuprofen $800 \mathrm{mg}$ orally every 8 hours for postoperative pain control in addition to hydrocodone/ acetaminophen. Two patients who reported no pain relief with hydrocodone were excluded from the study. Pain levels were assessed by obstetrical nurses, using a visual analog scale (VAS) of 0 to 10 , administered every 4- 6 hours. Patient characteristics, including age, race, weight, height, analgesic usage, pain levels, and side effects, were recorded on postoperative Day 3, at the time venous blood was obtained for OPRM1 and opioid determinations.

\section{Processing of Blood Samples}

Two $5 \mathrm{~mL}$ tubes of blood were obtained from each subject on the morning before their release from the University of Louisville Hospital. One sample (plasma) was collected in a purple top tube containing the anticoagulant EDTA, the other (serum) was collected in a red top tube containing a clotting activator. The blood 
sample containing EDTA was processed to form a buffy coat sample (white blood cells/leukocytes) by centrifugation for 15 minutes at $2000 \mathrm{xg}$ at room temperature, after which the leukocytes (middle layer) were aspirated from the tube and transferred into a $1.5 \mathrm{~mL}$ micro centrifuge tube. The second blood sample was allowed to clot and the serum portion was aspirated and transferred into a microcentrifuge tube. All samples were stored at $-80^{\circ} \mathrm{C}$ until analysis. The serum samples were sent to the Mayo Clinic (Rochester, MN) for LC-MS/MS analysis and quantitation of various opioids (described below).

\section{OPRM1 Genotyping}

Buffy coats were prepared from whole blood samples collected in EDTA anticoagulant. The EDTA tubes were spun for $10 \mathrm{~min}$ at $3300 \times \mathrm{g}$ at room temperature, and then the buffy coat was removed by pipetting. DNA isolation from buffy coats was performed using the QIAGEN EZ-1 BioRobot and Blood kit (QIAGEN, Inc. Valencia, CA). Laboratory specimens were analyzed using a laboratory-developed test employing polymerase chain reaction and allele-specific primer extension and fluorescence detection of the A118G OPRM1 SNP. Testing was designed, validated, and performed at Pharmacogenetic Diagnostic Laboratories (Louisville, KY) on a Luminex 100 xMAP IS System.

\section{LC-MS/MS Analysis for Opioids}

Morphine, codeine, oxycodone, oxymorphone, hydrocodone, hydromorphone, norhydrocodone, dihydrocodeine, and the deuterated compounds used as internal standards (IS) (morphine-D3, codeine-D3, oxycodone-D3, oxymorphone-D3, hydrocodone-D6, hydromorphone-D6) were purchased from Cerilliant (Round Rock, TX). All solvents were HPLC grade or better, and all chemicals were ACS grade. Briefly, $500 \mathrm{uL}$ of standards, controls, and samples; $50 \mathrm{uL}$ of internal standard (100 ng/mL); $3.0 \mathrm{~mL}$ of $0.1 \mathrm{M}$ phosphate buffer pH 6.0 were applied to preconditioned Clean Screen® Extraction Columns (United Chemical Technologies Inc.). The columns were washed with $2.0 \mathrm{~mL}$ of $0.1 \mathrm{M}$ phosphate buffer and $2.0 \mathrm{~mL}$ methanol.

The analytes were then eluted with $3.0 \mathrm{~mL}$ of methylene chloride:isopropyl alcohol:ammonium hydroxide (78:20:2, v/v/v). The extract was dried under nitrogen at $\leq 40^{\circ} \mathrm{C}$ and was reconstituted in $150 \mu \mathrm{L} 5 \%$ methanol in water and $50 \mu \mathrm{L}$ of the reconstituted extract was injected. The analytes were quantitated by using liquid chromatography tandem mass spectrometry (LC-MS/
MS). Chromatographic separation was achieved using a Shimadzu LC system, a LEAP auto sampler, and an ABI 5000 (Applied Biosystems) tandem mass spectrometer. The analytical column was a Discovery HSF5 $250 \mathrm{~mm}$ x $2.1 \mathrm{~mm}$ column (Sigma Aldrich \#567512-U). Chromatographic separation was achieved using a gradient consisting of Mobile Phase A (20mM ammonium formate $[\mathrm{pH}=3.0])$ and Mobile Phase B (100\% methanol). Detection was performed using electrospray ionization in positive ion mode. The concentrations were calculated by comparison of peak-area ratio of the drug to IS against those from the calibration curve. The limit of quantitation (LOQ) was determined to be $0.5 \mathrm{ng} /$ $\mathrm{mL}$ and the upper end of the linear range was $100 \mathrm{ng} /$ $\mathrm{mL}$ with correlation coefficients $(r)$ of the calibration curves consistently greater than 0.99 . Samples with concentrations exceeding the linearity were diluted with drug-free matrix. Inter-assay (between run) variability was $<10 \%$ throughout the analytical range.

\section{Data Analysis and Statistical Methods}

The primary outcome was self-reported pain, which was scored from 0 (no pain) to 10 (severe pain). Thirteen side effects were recorded, including confusion, constipation, dizziness, dry mouth, loss of appetite, nausea, pruritis, respiratory depression, sleep disturbance, somnolence, sweating, vomiting, and weakness, and scored from 1 to 3 according to increasing severity. The sum of symptoms was calculated. The symptoms were also rescored as presence/absence for analyses of individual association with OPRM1 genotype. The duration of treatment with hydrocodone ranged from 4 to 79.5 hours, with a median duration of 49 hours. The total number of doses of hydrocodone given was recorded and the total dose $(\mathrm{mg})$ during the course of treatment was calculated. BMI was calculated as weight $(\mathrm{kg}) /$ height $(\mathrm{m}) 2$.

Mean levels for study participant characteristics, including age, BMI, pain index, sum of side effects, total and average dose, and serum metabolites were calculated for OPRM1 genotype (AA versus AG/GG) and compared using t-tests. Regression analysis of variance was used to test differences between genotype group means adjusting for potential confounders. Multivariate regression was used to describe the association of the pain index with serum metabolite concentrations adjusting for dose, age, and body mass index, stratifying by OPRM1 genotype. Associations of OPRM1 with individual symptoms were measured using odds ratios and tested for statistical significance by the Chi-Square 
test. Statistical computations were performed using the Stata ${ }^{\circledR}$ statistical package (StataCorp LP, College Station, TX).

\section{Results}

Patients received an average of $7.1 \pm 2.5$ (range 1 13) doses of hydrocodone over the course of treatment, with an average total dose of $79.3 \pm 37.8 \mathrm{mg}$ (range 7.5 - 190). Descriptive characteristics of patients by OPRM1 genotype are shown in Table 1 . These analyses are limited to the 158 patients with complete genotype data. The OPRM1 genotype frequencies were homozygous for 118A (AA) 131 (82.9\%); heterozygous with (AG) genotype 22 (13.9\%); and homozygous for $118 \mathrm{G}$ (GG) $5(3.2 \%)$. The frequency of the $\mathrm{G}$ allele in our patient sample is $17.1 \%$, similar to that reported for the gen-

Table 1. Descriptive Characteristics by OPRM1 Genotype.

\begin{tabular}{|c|c|c|}
\hline & $\begin{array}{c}\mathbf{A A} \\
(\mathrm{n}=\mathbf{1 3 1})\end{array}$ & $\begin{array}{c}\text { AG/GG } \\
(\mathrm{n}=27)\end{array}$ \\
\hline Age (years) & $27.2(5.7)^{\star}$ & $29.7(6.2)$ \\
\hline BMI $(\mathrm{kg} / \mathrm{m} 2)^{* *}$ & $33.4(7.4)$ & $31.2(5.4)$ \\
\hline Pain Level ${ }^{* * *}$ & $4.4(2.4)$ & $4.3(2.0)$ \\
\hline Sum of side-effects & $4.4(4.1)$ & $6.4(5.7)$ \\
\hline Hydrocodone total dose (mg) & $80.6(39.2)$ & $73.1(30.0)$ \\
\hline \multicolumn{3}{|l|}{ Serum concentration $(\mathrm{ng} / \mathrm{ml})$} \\
\hline Hydrocodone & $27.6(24.2)$ & $28.4(20.7)$ \\
\hline Hydromorphone & $4.8(7.7)$ & $6.3(8.0)$ \\
\hline Dihydrocodeine & $1.8(1.6)$ & $1.9(1.3)$ \\
\hline Norhydrocodone & $6.4(5.0)$ & $7.4(5.2)$ \\
\hline
\end{tabular}

${ }^{\star}$ Mean $\pm \mathrm{SD} ;{ }^{* *} \mathrm{BMI}$ is for post-delivery; ${ }^{* * *}$ Two patients had missing data for the pain level; ${ }^{* * *} P<0.04$; t-test

Table 2. Serum concentrations of other opioids by OPRMI Genotype.

\begin{tabular}{|l|c|c|c|c|c|c||}
\hline \multirow{2}{*}{$\begin{array}{c}\text { Serum concentration } \\
(\mathbf{n g} / \mathbf{m l})\end{array}$} & \multicolumn{4}{|c|}{ AA } & \multicolumn{3}{c|}{ AG/GG } \\
\cline { 2 - 8 } & N & Mean & SD & N & Mean & SD \\
\hline Oxymorphone & 12 & 15.0 & 28.7 & 1 & 32.6 & --- \\
\hline Oxycodone & 16 & 14.4 & 18.6 & 4 & 8.6 & 11.0 \\
\hline Morphine & 17 & 5.8 & 6.8 & 2 & 2.7 & 0.1 \\
\hline Codeine & 7 & 6.7 & 11.7 & 1 & 0.6 & --- \\
\hline
\end{tabular}

Results from 43 patients, several of which had more than one opioid detected in serum samples not derived from hydrocodone. Morphine may have been derived from spinal or parenteral morphine administered during the first day of the study or from codeine. Serum concentrations of morphine and codeine were probably subtherapeutic. Oxymorphone and oxycodone levels were in the therapeutic range. Excluding these patients did not materially change the association of OPRM1 with any of the variables, including the sum of side-effects, which remained statistically significant $(P<0.05$; t-test $)$ eral population (www.ncbi.nlm.nih.gov/projects/SNP/ snp_ref.cgi?rs=1799971; accessed 2/25/2013). Because there were too few patients with the GG genotype to allow separate statistical analysis of that subgroup, they were grouped together with AG heterozygous patients in a recessive genetic model. Comparison of mean characteristics revealed no statistically significant differences between genotypes except for the sum of side effects, which was higher in patients with $A G / G G$ (mean $=6.4)$ than AA genotype (mean $=4.4 ; \mathrm{t}=-2.05, P$ $<0.04)$. This difference remained statistically significant regardless of adjustment for age, BMI, pain level, or total dose.

Table 2 shows the concentrations of opioid metabolites, some not derived from hydrocodone, such as oxymorphone, oxycodone, and codeine that were detected in the sera of 43 subjects. In total, 29 patients had detectable levels of at least one metabolite and 14 patients had levels of 2 or more metabolites. Thirteen patients had detectable levels of oxymorphone, 20 oxycodone, and 8 codeine. This suggests that these patients violated the study protocol. In addition, 19 patients had low levels of morphine, perhaps due to spinal morphine, supplemental parenteral morphine administered during the first 24 hours following surgery, or derived from codeine. Excluding these patients did not materially change the association of OPRM 1 genotype with any of the variables. The sum of side effects remained statistically significant ( $P<0.05$; t-test).

Table 3 shows results for the regression of the pain level on serum hydromorphone and Table 4 presents the analysis for serum hydrocodone adjusted for total hydrocodone dose, age, and BMI, by OPRM1 genotype. Pain relief for patients homozygous for AA was significantly associated with total dose of hydrocodone $(P=$ $0.01)$ and serum hydromorphone level $(P=0.004)$, while there were no associations with AG/GG genotypes. In contrast, there was no association between the pain level, total hydrocodone dose, and serum hydrocodone concentration with either genotype. Adjusting for the difference in treatment during surgery between the first 40 patients and the remaining 118 did not materially alter the associations of the pain level with either serum hydromorphone or hydrocodone in patients with $A A$ versus $A G / G G$ genotypes.

The modification of the association of serum hydromorphone with pain relief by the OPRM1 polymorphism is visually displayed in Fig. 1. Serum hydromorphone concentrations in this graph were adjusted for total hydrocodone dose by regressing concentration 
Table 3. Association of Pain Level with Serum Hydromorphone by OPRM1 Genotype.

\begin{tabular}{|l|l|l|l|l|l|l||}
\hline \multicolumn{2}{|l}{} & AA (n = 129)* & \multicolumn{2}{l|}{ AG/GG (n = 27) } \\
\hline Variable & beta & s.e & P-value & beta & s.e. & P-value \\
\hline Hydrocodone total dose (mg) & 0.009 & 0.005 & 0.010 & 0.008 & 0.014 & 0.554 \\
\hline Serum Hydromorphone (ng/ml) & -0.085 & 0.029 & 0.004 & 0.019 & 0.053 & 0.724 \\
\hline Age (years) & -0.031 & 0.037 & 0.395 & -0.020 & 0.070 & 0.784 \\
\hline BMI (kg/m2) & -0.046 & 0.029 & 0.102 & 0.041 & 0.081 & 0.617 \\
\hline
\end{tabular}

${ }^{*}$ Sample size reduced due to missing data for pain level.

$P$-values are shown in the table. Multivariate regression analysis (F-test) was used to determine statistical significance for pain level, total hydrocodone dose, serum hydromorphone, age, and BMI. Total hydrocodone dose and serum hydromorphone concentration were significantly correlated with pain level only in the AA genotype group. See Table 4.

Table 4. Association of Pain Level with Serum Hydrocodone by OPRM1 Genotype.

\begin{tabular}{|c|c|c|c|c|c|c|}
\hline \multirow[b]{2}{*}{ Variable } & \multicolumn{3}{|c|}{$\mathrm{AA}(\mathrm{n}=129)^{*}$} & \multicolumn{3}{|c|}{ AG/GG (n = 27) } \\
\hline & beta & s.e & P-value & beta & s.e. & P-value \\
\hline Hydrocodone total dose (mg) & 0.009 & 0.007 & 0.166 & 0.011 & 0.015 & 0.496 \\
\hline Serum Hydrocodone (ng/ml) & -0.007 & 0.011 & 0.511 & -0.008 & 0.024 & 0.742 \\
\hline Age (years) & -0.013 & 0.038 & 0.735 & -0.017 & 0.072 & 0.820 \\
\hline BMI (kg/m2) & -0.033 & 0.029 & 0.257 & 0.038 & 0.083 & 0.660 \\
\hline
\end{tabular}

*Sample size reduced due to missing data for pain level.

P-values are shown in the table. Multivariate regression analysis (F-test) was used to determine statistical significance for pain level, total hydrocodone dose, serum hydrocodone, age, and BMI. Total hydrocodone dose was not significantly related to pain level and serum hydrocodone concentration in either genotype group. See Table 3.

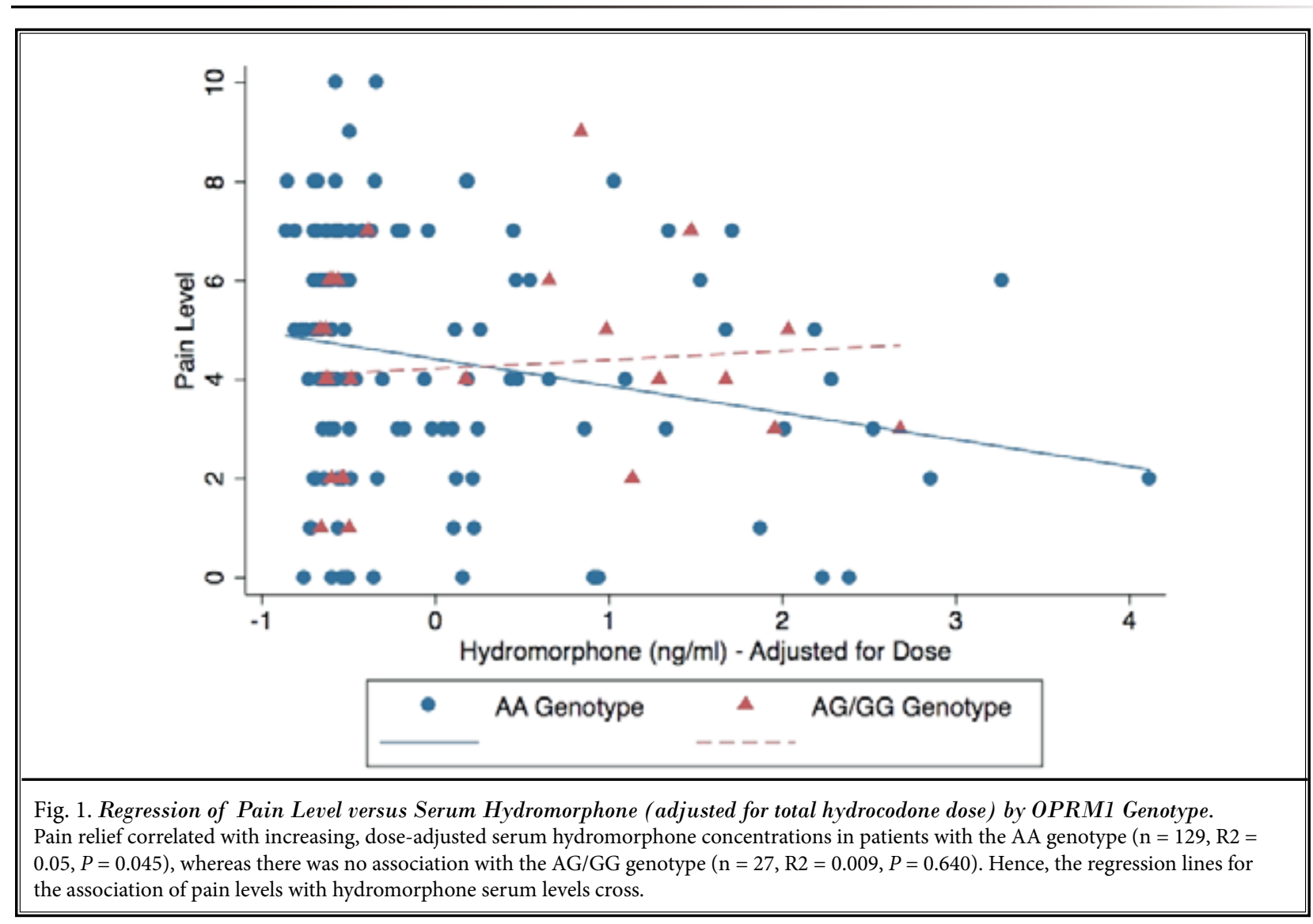


on dose, calculating the residuals, and adding these to mean concentration. Pain scores were inversely associated with increasing, dose-adjusted serum hydromorphone concentration in patients with the AA genotype ( $n=129, \mathrm{R} 2=0.05, P=0.045$ ), while there was no association in those with the AG/GG genotype ( $n=27, R 2$ $=0.009, P=0.640$ ); hence, the regression lines for the association of pain levels with serum hydromorphone concentrations cross. Excluding the 43 subjects with other opioid metabolites did not materially affect these results. The association of pain relief with serum hydromorphone remained statistically significant in patients with the AA genotype $(P=.033)$, but not in those with the $\mathrm{G}$ allele.

The frequency of individual side effects evaluated in this study is shown by OPRM1 genotype in Table 5. Patients with the AG/GG genotype were 2 to 2.5 times more likely to report constipation, dizziness, dry mouth, vomiting, and weakness, and 5 times more likely to report respiratory depression. Thus, patients with the $\mathrm{G}$ allele of OPRM1 were less likely to report pain relief with increasing doses of hydrocodone and serum hydromorphone concentrations, and more likely to report side effects.

\section{Discussion}

This study compared analgesia and side effect profiles with total hydrocodone dose, quantitative plasma hydrocodone and hydromorphone concentrations, and A118G OPRM1 genotype in patients following Cesarean section. All patients received spinal anesthesia with spinal morphine or supplemental parenteral morphine for pain control during the initial 24 hours following surgery. Opioid requirements, pain levels, and venous plasma samples were obtained on postoperative day 3 , to minimize the chances of residual analgesic effects of spinal or parenteral morphine.

By multivariate regression analysis, postoperative pain relief was associated with total hydrocodone dose in OPRM1 AA patients, but not in patients with the $G$ allele. However, pain relief correlated with serum hydromorphone concentrations and not with hydrocodone concentrations. In addition to showing a correlation of OPRM1 AA with analgesia, this study suggests that pain relief with hydrocodone was due to its metabolite, hydromorphone. This finding is consistent with recently reported binding constants of hydromorphone (Ki 0.36 $\mathrm{nM}$ ) and hydrocodone (Ki $41.58 \mathrm{nM}$ ) for the OPRM1 receptor, indicating that hydrocodone has 115-fold less affinity than hydromorphone for the receptor (14). By comparison, morphine has a $\mathrm{Ki}$ of 1.168. Although an earlier study showed that hydrocodone had a 30-fold less affinity than hydromorphone for the mu receptor, the authors used rat brain homogenates (15). Nonetheless, they suggested that some of the analgesic activity associated with hydrocodone was due to its hydromor-

Table 5. Frequency of Side-Effects by OPRM1 Genotype.

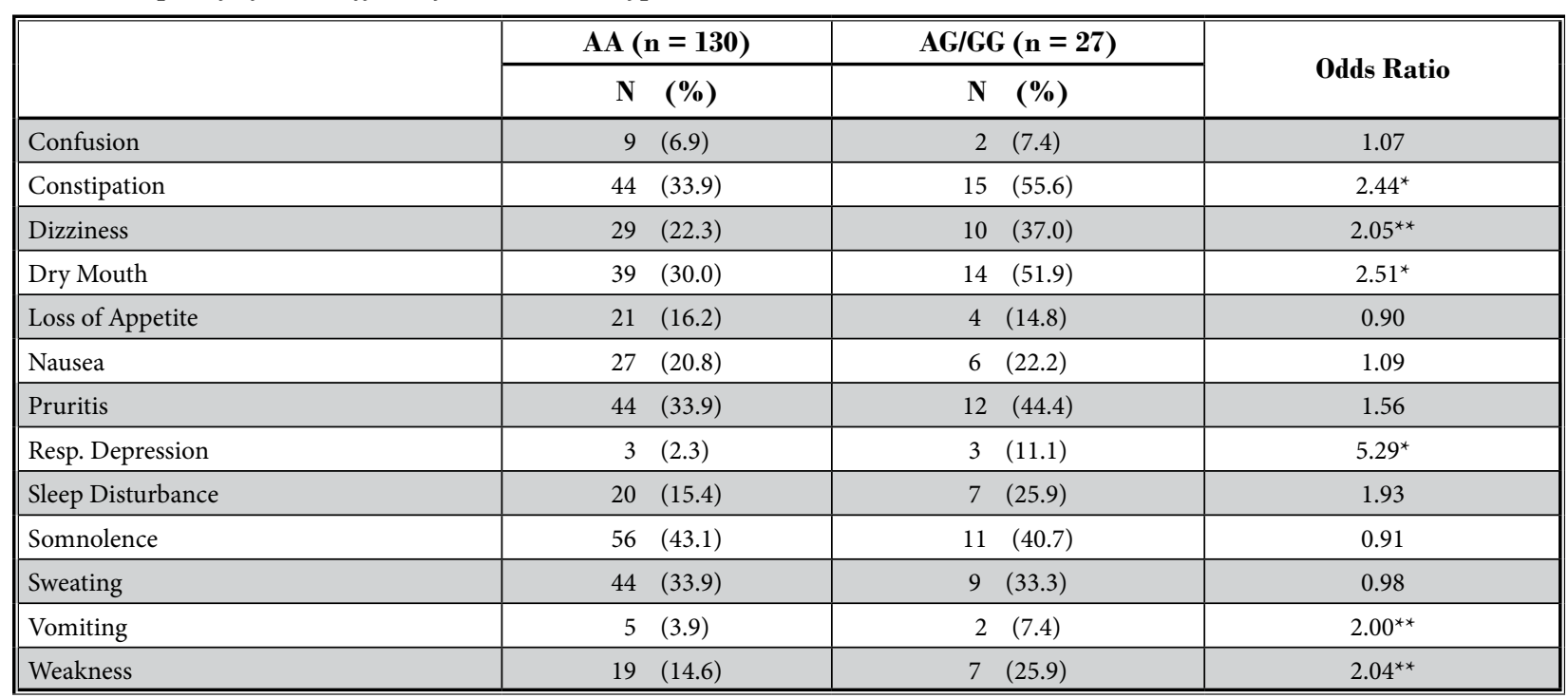

${ }^{*} P<0.05 ;{ }^{* *} P<0.10$; Statistical significance by Chi-Square test.

Constipation, dry mouth, and respiratory depression occurred more frequently in AG/GG patients than AA patients. See Table 1. 
phone metabolite. In view of our finding that pain relief did not correlate with hydrocodone serum levels, even in the AA patients, our observation provides further evidence that hydrocodone is a pro-drug for hydromorphone, recognizing that hydrocodone may also have intrinsic analgesic effect at the mu receptor at usual analgesic doses (13).

Forty-three patients had trace levels of one or more other opioids (oxymorphone, oxycodone, codeine) in their sera. With the possible exception of those with trace levels of morphine, which was administered to some patients during the first 24 hours after Cesarean section, this suggests that these patients had access to drugs other than hydrocodone prescribed in the study protocol. However, the exclusion of these patients did not materially alter the results of the statistical analyses. In addition, adjusting for the use of spinal morphine did not significantly alter the results.

Although the contribution of acetaminophen to postoperative analgesia in this study is unclear, acetaminophen alone would not be expected to provide satisfactory pain relief as the sole analgesic following Cesarean section. Because all opioid formulations in this study contained acetaminophen, the presence of acetaminophen per se does not appear to confound the results attributed to the interaction of opioids and the OPRM1 receptor alleles.

Several proposed molecular mechanisms may explain the reduced analgesic effect of mu opioids in subjects with the $G$ allele of OPRM1. Subjects with the A allele exhibit significantly higher levels of morphine binding than those with the $G$ allele (16). As well, the AG genotypes may produce a less functional variant of OPRM1, by reducing $\mathrm{mRNA}$ transcription and protein levels of OPRM1. The physiologic consequences could include less receptor binding sites for mu opioids, resulting in less pain relief. Conversely, a study examining human postmortem brain tissue from areas that process nociception (somatosensory cortex) found that OPRM1 receptor densities were the same in the $A A$ and GG subjects (17). However, mu receptor coupling with Gprotein was only $58 \%$ as efficient in the $G$ variant as in homozygous A carriers. Similarly, a recent study using a humanized mouse sensory neuronal cell line did not find a difference in receptor density between OPRM1 alleles, but did observe a 5-fold decrease in potency and a $26 \%$ reduction in morphine efficacy at the receptor with the $G$ variant (18). No differences were noted with fentanyl in this model. This suggests that pharmacologic responses to opioid agonists may be ligand-dependent.
Clinically, this indicates that it is important to examine specific opioids (e.g., hydrocodone) when investigating analgesic responses with OPRM1 variants. This may also be true when considering side effects.

In our study, AG/GG patients had a statistically higher frequency of constipation, dry mouth, and respiratory depression. Why $\mathrm{G}$ carriers should have a higher opioid side effect profile with hydrocodone is unclear. Walter and Lotsch (9) noted slightly less nausea in their GG subjects. Also, as Ray et al (19) suggested, it may be naive to propose that alterations at position 118 produce only a gain or loss of function.

The complexity of opioid receptor function and the diverse number of possible ligand-receptor interactions must be considered when evaluating the clinical implications of genetic variants of OPRM1. The ultimate opioid effect, whether analgesic or side effect, may reflect a balance of endogenous and exogenous opioid agonists at OPRM1. For example, the $118 \mathrm{G}$ variant has been reported to produce higher mu receptor affinity for the endogenous opioid ligand, beta endorphin (20), which could alter the apparent sensitivity to exogenous opioids, such as hydrocodone. Moreover, different opioid drugs that act at OPRM1 may have variable clinical profiles that reflect summative effects at OPRM1 and opioid receptor subtypes (21).

Limitations of the current study include the relatively small sample sizes involved. Twenty-seven patients had the $\mathrm{G}$ allele variant and only 5 were homozygous for GG. Thus, we could not examine results by allele-dose for patients with the $\mathrm{G}$ allele. Additionally, a confounding role of pregnancy in the observed analgesic responses to hydrocodone cannot be excluded, because this study examined only post-Cesarean section patients. Thus, these results may not be directly applicable to postoperative men or non-pregnant women patients.

In summary, our study found a significant correlation between pain relief and total hydrocodone dose in patients with the AA variant of OPRM1 at the 118 position. However, pain relief did not correlate with serum concentrations of hydrocodone, but rather with concentrations of hydromorphone, the active metabolite of hydrocodone. Thus, our data suggest that hydromorphone was the active opioid analgesic, and that hydrocodone served as a prodrug for hydromorphone. Although pain relief in patients carrying the $G$ allele did not correlate with opioid dose or concentration, total opioid side effects were more common in this group. At present, the molecular mechanisms that could explain these findings are poorly understood. 
Our results suggest that future studies should evaluate the relationship of OPRM1 variants and pain relief in terms of serum opioid concentrations, not just total opioid consumption. Moreover, because OPRM1 variant effects may be opioid-specific and modified by the presence of active opioid metabolites, future studies should evaluate serum levels of metabolites of the opioid under investigation. In addition, pharmacogenetic testing, such as genotyping the CYP450 enzymes responsible for the generation of the metabolites, may improve our understanding of the role of OPRM1 in the pharmacodynamics of specific opioid drugs. In turn, this may improve the clinical predictive value of pharmacogenetic testing of OPRM1 and aid in the design of opioid analgesics with an improved therapeutic index.

\section{Acknowledgments}

The study project was made possible by assistance and contributions of various individuals and entities. At
University of Louisville, Dr. Andrew W. Moore, Dr. Jonathan Metry, and Mrs. Suzanne McGee (medical student) assisted with patient enrolment, Mrs. Sherrie Goss, RN, assisted with IRB application, Mary Embry and Tondra Young, Mr. Edward P. Womack, and Ms. Elizabeth Hudson helped with blood sample processing, handling, and other study tasks. At PGXL Laboratories, Dr. Kristen Reynolds and Ms. Nancy Johnson assisted with the OPRM1 genotyping. At Mayo Clinic Laboratory, Mr. Eric W. Korman assisted with the LC-MS/MS analysis. This project was funded in parts by the Forensic Toxicology Program at University of Louisville (Dr. Jortani) as well as contributions through providing testing by PGXL Laboratories and Mayo Clinic's Toxicology and Drug Monitoring Laboratory. Authors would like to thank all nurses and clinicians at University of Louisville Hospital as well as Dr. Sean Barnes (Department of Pathology and Laboratory Medicine) for their help and excellent contributions.

\section{References}

1. Klepstad P, Rakvag TT, Kaasa S, Holthe M, Dale O, Borchgrevink PC, Baar C, Vikan T, Krokan HE, Skorpen F. The $118 \mathrm{~A}>\mathrm{G}$ polymorphism in the human mu-opioid receptor gene may increase morphine requirements in patients with pain caused by malignant disease. Acta Anaesthesiol Scand 2004; 48:1232-1239.

2. Chou WY, Wang CH, Liu PH, Liu CC, Tseng CC, Jawan B. Human opioid receptor A118G polymorphism affects intravenous patient-controlled analgesia morphine consumption after total abdominal hysterectomy. Anesthesiology 2006; 105:334-337.

3. Chou WY, Yang LC, Lu HF, Ko JY, Wang $\mathrm{CH}$, Lin SH, Lee TH, Concejero A, Hsu C). Association of mu-opioid receptor gene polymorphism (A118G) with variations in morphine consumption for analgesia after total knee arthroplasty. Acta Anaesthesiol Scand 2006; 50:787-792.

4. Campa D, Gioia A, Tomei A, Poli P, Barale R. Association of $A B C B 1 / M R_{1}$ and $\mathrm{OPRM}_{1}$ gene polymorphisms with morphine pain relief. Clin Pharmacol Ther 2008; 83:559-566.

5. Sia AT, Lim Y, Lim EC, Goh RW, Law HY, Landau R, Teo YY, Tan EC. A118G single nucleotide polymorphism of human mu-opioid receptor gene influences pain perception and patient-controlled intravenous morphine consumption after intrathecal morphine for postc- esarean analgesia. Anesthesiology 2008; 109:520-526.

6. De Capraris A, Cinnella G, Marolla A, Salatto P, Da Lima S, Vetuschi P, Consoletti L, Gesualdo L, Dambrosio M. Micro opioid receptor Aı18G polymorphism and post-operative pain: Opioids' effects on heterozygous patients. Int J Immunopathol Pharmacol 2011; 24:993-1004.

7. Zhang W, Yuan JJ, Kan QC, Zhang LR, Chang YZ, Wang ZY. Study of the OPRM Al18G genetic polymorphism associated with postoperative nausea and vomiting induced by fentanyl intravenous analgesia. Minerva Anestesiol 2011; 77:33-39.

8. Oertel BG, Schmidt R, Schneider A, Geisslinger G, Lotsch J. The mu-opioid receptor gene polymorphism $118 \mathrm{~A}>\mathrm{G}$ depletes alfentanil-induced analgesia and protects against respiratory depression in homozygous carriers. Pharmacogenet Genomics 2006; 16:625-636.

9. Walter $C$, Lotsch J. Meta-analysis of the relevance of the OPRM $1118 \mathrm{~A}>\mathrm{G}$ genetic variant for pain treatment. Pain 2009; 146:270-275.

10. Klepstad P, Fladvad T, Skorpen F, Bjordal K, Caraceni A, Dale O, Davies A, Kloke $M$, Lundström S, Maltoni M, Radbruch L, Sabatowski R, Sigurdardottir V, Strasser F, Fayers PM, Kaasa S. Influence from genetic variability on opioid use for cancer pain: A European genetic association study of 2294 cancer pain patients. Pain
2011; 152:1139-1145.

11. Cone EJ, Darwin WD, Gorodetzky CW, Tan T. Comparative metabolism of hydrocodone in man, rat, guinea pig, rabbit, and dog. Drug Metab Dispos 1978; 6:488-493.

12. Otton SV, Schadel M, Cheung SW, Kaplan HL, Busto UE, Sellers EM. CYP2D6 phenotype determines the metabolic conversion of hydrocodone to hydromorphone. Clin Pharmacol Ther 1993; 54:463-472.

13. Thompson CM, Wojno H, Greiner E, May EL, Rice KC, Selley DE. Activation of $\mathrm{G}$-proteins by morphine and codeine congeners: insights to the relevance of $\mathrm{O}$ - and $\mathrm{N}$-demethylated metabolites at mu- and delta-opioid receptors. J Pharmacol Exp Ther 2004; 308:547-554.

14. Volpe DA, McMahon Tobin GA, MelIon RD, Katki AG, Parker RJ, Colatsky T, Kropp TJ, Verbois SL. Uniform assessment and ranking of opioid mu receptor binding constants for selected opioid drugs. Regul Toxicol Pharmacol 2011; 59:385-390.

15. Chen ZR, Irvine RJ, Somogyi AA, Bochner $\mathrm{F}$. $\mathrm{Mu}$ receptor binding of some commonly used opioids and their metabolites. Life Sci 1991; 48:2165-2171.

16. Zhang Y, Wang D, Johnson AD, Papp AC, Sadee W. Allelic expression imbalance of human mu opioid receptor (OPRMı) caused by variant A118G. J Biol Chem 
2005; 280:32618-32624.

17. Oertel BG, Kettner M, Scholich K, Renne C, Roskam B, Geisslinger G, Schmidt $\mathrm{PH}$, Lotsch J. A common human microopioid receptor genetic variant diminishes the receptor signaling efficacy in brain regions processing the sensory information of pain. J Biol Chem 2009; 284:6530-6535.

18. Mahmoud S, Thorsell A, Sommer WH Heilig M, Holgate JK, Bartlett SE, RuizVelasco V. Pharmacological consequence of the Al18G mu opioid receptor polymorphism on morphine- and fentanylmediated modulation of $\mathrm{Ca}(2)$ channels in humanized mouse sensory neurons. Anesthesiology 2011; 115:1054-1062.

19. Ray R, Ruparel K, Newberg A, Wileyto $E P$, Loughead JW, Divgi C, Blendy JA, Logan J, Zubieta JK, Lerman C. Human Mu Opioid Receptor (OPRMı A $118 \mathrm{G}$ ) polymorphism is associated with brain mu-opioid receptor binding potential in smokers. Proc Natl Acad Sci U S A 2011;
108:9268-9273.

20. Kroslak T, LaForge KS, Gianotti RJ, Ho A, Nielsen DA, Kreek MJ. The single nucleotide polymorphism Aı18G alters functional properties of the human mu opioid receptor. J Neurochem 2007; 103:77-87.

21. Pasternak GW. Preclinical pharmacology and opioid combinations. Pain Med 2012; 13 Suppl 1:S4-S11. 
